\title{
Transcriptional profiling of breast cancer cells in response to mevinolin: Evidence of cell cycle arrest, DNA degradation and apoptosis
}

\author{
ALI M. MAHMOUD ${ }^{1,2}$, MOURAD A.M. ABOUL-SOUD ${ }^{1,3}$, JUNKYU HAN ${ }^{4,5}$, \\ YAZEED A. AL-SHEIKH ${ }^{3}$, AHMED M.AL-ABD ${ }^{6}$ and HANY A. EL-SHEMY ${ }^{1}$ \\ ${ }^{1}$ Department of Biochemistry, Faculty of Agriculture, Cairo University, Giza $12613 ;{ }^{2}$ Centre for Aging and Associated \\ Diseases, Helmy Institute for Medical Sciences, Zewail City of Science and Technology, Giza 12588, Egypt; \\ ${ }^{3}$ Chair of Medical and Molecular Genetics Research, Department of Clinical Laboratory Sciences, \\ College of Applied Medical Sciences, King Saud University, Riyadh 11433, Kingdom of Saudi Arabia; \\ ${ }^{4}$ Graduate School of Life and Environmental Sciences; ${ }^{5}$ Alliance for Research on North \\ Africa (ARENA), University of Tsukuba, Tsukuba, Ibaraki 305-8572, Japan; ${ }^{6}$ Department \\ of Pharmacology, Medical Division, National Research Centre, Cairo 21622, Egypt
}

Received January 29, 2015; Accepted March 3, 2016

DOI: $10.3892 /$ ijo.2016.3418

\begin{abstract}
The merging of high-throughput gene expression techniques, such as microarray, in the screening of natural products as anticancer agents, is considered the optimal solution for gaining a better understanding of the intervention mechanism. Red yeast rice (RYR), a Chinese dietary product, contains a mixture of hypocholesterolemia agents such as statins. Typically, statins have this effect via the inhibition of HMG-CoA reductase, the key enzyme in the biosynthesis of cholesterol. Recently, statins have been shown to exhibit various beneficial antineoplastic properties through the disruption of tumor angiogenesis and metastatic processes. Mevinolin (MVN) is a member of statins and is abundantly present in RYR. Early experimental trials suggested that the mixed apoptotic/necrotic cell death pathway is activated in response to MVN exposure. In the current study, the cytotoxic profile of MVN was evaluated against MCF-7, a breast cancer-derived cell line. The obtained results indicated that MVN-induced cytotoxicity is multi-factorial involving several regulatory pathways in the cytotoxic effects of MVN on breast cancer cell
\end{abstract}

Correspondence to: Professor Mourad A.M. Aboul-Soud, Chair of Medical and Molecular Genetics Research, Department of Clinical Laboratory Sciences, College of Applied Medical Sciences, King Saud University, P.O. Box 10219, Riyadh 11433, Kingdom of Saudi Arabia

E-mail: maboulsoud@ksu.edu.sa

Professor Hany A. El-Shemy, Department of Biochemistry, Faculty of Agriculture, Cairo University, Gamaa Street, Giza 12613, Egypt

E-mail: helshemy@hotmail.com

Key words: mevinolin, microarray, MCF-7, natural products, $\mathrm{p} 53$ lines. In addition, MVN-induced transcript abundance profiles inferred from microarrays showed significant changes in some key cell processes. The changes were predicted to induce cell cycle arrest and reactive oxygen species generation but inhibit DNA repair and cell proliferation. This MVN-mediated multi-factorial stress triggered specific programmed cell death (apoptosis) and DNA degradation responses in breast cancer cells. Taken together, the observed MVN-induced effects underscore the potential of this ubiquitous natural compound as a selective anticancer activity, with broad safety margins and low cost compared to benchmarked traditional synthetic chemotherapeutic agents. Additionally, the data support further pre-clinical and clinical evaluations of $\mathrm{MVN}$ as a novel strategy to combat breast cancer and overcome drug resistance.

\section{Introduction}

Natural products of plants provide an abundant source of potentially active compounds for the treatments of different disorders (1,2). Far Eastern, Middle Eastern, Saharan, and tropical regions are among the richest sources of natural products in the world. The isolation and purification of active fractions and active ingredients among potentially active natural products has received increased scientific and industrial interest (2).

Red yeast rice (RYR), a Chinese dietary product made by fermenting ordinary rice with the mold Monascus purpureus, has been widely used as a food condiment and colorant in several Asian countries (3). RYR has been used for centuries without any reports of health hazards or long-term toxicity (4). Several medicinally active ingredients were isolated from RYR including monacholin-K, mevinolin (MVN; lovastatin), $\gamma$-aminobutyric acid, di-merumic acid, sterols $(\beta$-sitosterol, campesterol, stigmasterol and sapogenin), isoflavones and mono-unsaturated fatty acids $(3,4)$. 
MVN or lovastatin is a potent HMGCo-A reductase enzyme inhibitor that has been shown to interfere with de novo steroidogenesis (5). MVN was used clinically for the treatment of hypercholesterolemia with extremely good patient tolerance profiles $(6,7)$. In the last decade, epidemiological studies (8) have drawn attention to the possible beneficial roles of HMGCo-A reductase inhibitors (statins), such as MVN, in neoplastic disorders. Some members of the statin group may reduce the recurrence of cancer after radical prostatectomy (9). Additionally, a marked reduction in the incidence of lipoma was observed for statin-treated patients (10). Of note, a negative association was reported between the use of HMGCo-A reductase inhibitors and cancer incidence in veteran populations (11). Investigators focused on the ability of MVN and other statins to sensitize tumor cells for conventional chemotherapeutics (12).

Previous experimental reports manifested a potential anti-cancer activity of MVN and other HMGCo-A reductase inhibitors per se (13). However, the exact signaling mechanisms involved in $\mathrm{MVN}$-induced cell death remain controversial. Few reports attribute the anti-cancer activity of MVN to the induction of apoptosis (14), while other studies negate any role of apoptosis in MVN-induced cell death (15). Thus, whether the apoptotic pathway is involved in MVN-induced cytotoxicity, or not, remained an open issue by 2012. The resolution of the mechanism of MVN may improve understanding of its anti-cancer effects and suggest the likelihood of the emergence of resistance among cancer cell lines.

MVN has been shown to inhibit cell proliferation and induce apoptosis and necrosis in several experimental settings including that of breast cancer, thus making them potential anticancer agents. Multisignaling distortion effects have been observed by statin treatment. Klawitter et al suggested that the anti-proliferative and apoptotic effects of statins on breast cancer cells occurs due to the induction effect on reactive oxygen species (ROS). Additionally, statins increase the level of nitric oxide (NO) through the induction of inducible nitric oxide synthase (iNOS) (14).

In the present study, the expression of markers of apoptosis was investigated in response to MVN treatment in MCF-7 breast cancer cells. Microarrays tested the transcript abundances of thousands of genes. The involvement of several regulatory pathways in the cytotoxic effects of MVN on breast cancer cell lines was shown. A model for the plausible mode-of-action of MVN-mediated in vitro cytotoxicity against breast cancer was also described.

\section{Materials and methods}

Chemicals and drugs. Doxorubicin (DOX) is a cytotoxic anthracycline originally isolated from Streptomyces peucetius which has been used as a chemotherapeutic agent. DOX was used as a positive control in quantitative polymerase chain reaction (qPCR) and caspase-3 (EC 3.4.22.56) experiments. DOX and MVN were purchased from Sigma Aldrich Chemical Co. (St. Louis, MO, USA). RPMI-1640 media, fetal bovine serum and other cell culture materials were purchased from Fisher Scientific, Cell Culture (Houston, TX, USA). Other reagents were of the highest analytical grade available.
Cell culture. Human transformed cell lines, from the breast (MCF-7) line were obtained from Vacsera (Giza, Egypt). Vacsera identified the cell line prior to conducting these studies. The cells were maintained in RPMI-1640 supplemented with $100 \mu \mathrm{g} / \mathrm{ml}$ streptomycin, $100 \mu \mathrm{g} / \mathrm{ml}$ penicillin and $10 \%(\mathrm{w} / \mathrm{v})$ heat-inactivated fetal bovine serum in a humidified, $5 \%(\mathrm{v} / \mathrm{v})$ $\mathrm{CO}_{2}$ atmosphere incubator at $37^{\circ} \mathrm{C}$.

Cytotoxicity assays. The cytotoxicity of MVN was tested against MCF-7 cells using an MTT assay. Exponentially growing cells were collected using $0.25 \%(\mathrm{w} / \mathrm{v})$ trypsin-EDTA and plated in 96-well plates at $2.0 \times 10^{3}$ cells/well. After $24 \mathrm{~h}$ incubation, the cells were exposed to each test compound for $72 \mathrm{~h}$ and washed with phosphate-buffered saline (PBS). Then, fresh $100 \mu \mathrm{l}$ media with $10 \mu \mathrm{l}$ MTT at $5 \mathrm{mg} / \mathrm{ml}$ in PBS were added. After overnight incubation the colored form of Heidenhain's Azan trichrome stain was dissolved in $100 \mu \mathrm{l}$ of $10 \%(\mathrm{w} / \mathrm{v})$ SDS and the absorbance at $570 \mathrm{~nm}$ was determined using a multi-detection microplate reader. The cell viability was presented as a percentage of the control.

Data analysis. The dose response curve of compounds was analyzed using the $\mathrm{E}_{\max }$ model:

$$
\% \text { Cell viability }=(100-\mathrm{R}) \times\left(1-\frac{[\mathrm{D}]^{\mathrm{m}}}{\mathrm{K}_{\mathrm{d}}{ }^{\mathrm{m}}+[\mathrm{D}]^{\mathrm{m}}}\right)+\mathrm{R}
$$

$\mathrm{R}$ was the residual unaffected fraction (the resistance fraction), [D] was the drug concentration used, $\mathrm{K}_{\mathrm{d}}$ was the drug concentration that produces a $50 \%$ reduction of the maximum inhibition rate, and $\mathrm{m}$ was a Hill-type coefficient. The $\mathrm{IC}_{50}$ was defined as the drug concentration required to reduce absorbance to $50 \%$ of that of the control (i.e., $\mathrm{K}_{\mathrm{d}}=\mathrm{IC}_{50}$ when $\mathrm{R}$ was 0 and $\mathrm{E}_{\max }$ was $\left.100-\mathrm{R}\right)(16)$.

Caspase-3 activity in MCF-7 treated cells with $I_{50}$ of DOX and $M V N$. Cells were harvested after treatment for $72 \mathrm{~h}$ with the pre-determined $\mathrm{IC}_{50}$ of DOX and MVN. Caspase-3 activity was determined using a Quantikine-immunoassay ${ }^{\mathrm{TM}}$ kit (R\&D Systems, Inc., Minneapolis, MN, USA) according to the manufacturer's instructions. Plates were then read at $450 \mathrm{~nm}$ with wavelength correction at $540 \mathrm{~nm}$ using microwell-plate absorbance reader (ELx 808; Bio-Tek Instruments, Inc., Winooski, VT, USA). A standard curve was constructed and the amount of active caspase- 3 in the treated samples was calculated.

\section{Microarray analysis for MVN-treated MCF-7 cells}

RNA isolation. MCF-7 cells were resuspended at a concentration of $2.0 \times 10^{4}$ cells $/ \mathrm{ml}$ after $24 \mathrm{~h}$ incubation. The cells were treated with or without MVN $\mathrm{IC}_{50}$ for $4 \mathrm{~h}$. Total RNA was extracted from the cells using $1 \mathrm{ml}$ of Isogen ${ }^{\mathrm{TM}}$ (Nippon Gene Co., Ltd., Tokyo, Japan) following the manufacturer's instructions. Isolated RNA was ethanol precipitated, quantified and quality assessed by a Nano-Drop 2000 spectrophotometer (Thermo Fisher Scientific, Wilmington, DE, USA). Total RNA (500 ng) was used for reverse transcription when the $\mathrm{OD}_{260} / \mathrm{OD}_{280}$ ratio was 1.8-2.0. RNA samples were prepared as duplicates. The experiments were repeated. 

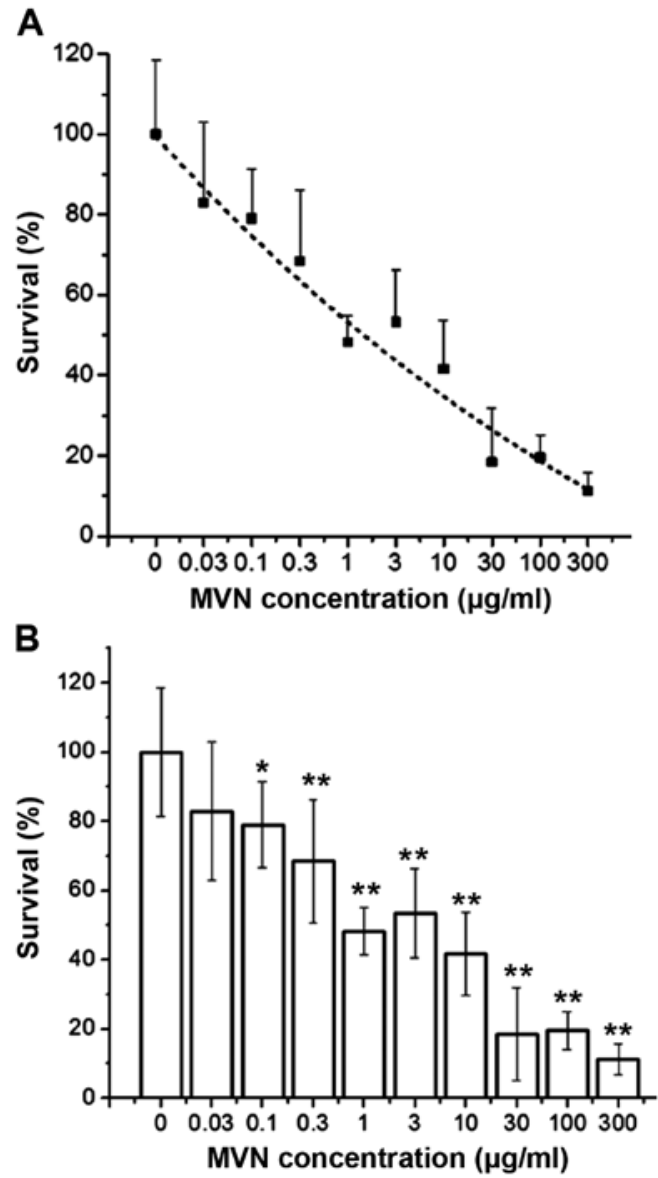

Figure 1. The effect of mevinolin (MVN) on the MCF-7 cell line. (A and B) Cells were exposed to serial dilutions of MVN for $72 \mathrm{~h}$. Cell viability was determined using an MTT assay. Data are presented as means \pm standard deviation $(n=3)$. The t-test was used to analyze the results of different MVN concentrations compared to the control group, ${ }^{*} \mathrm{P}<0.5,{ }^{* *} \mathrm{P}<0.1$

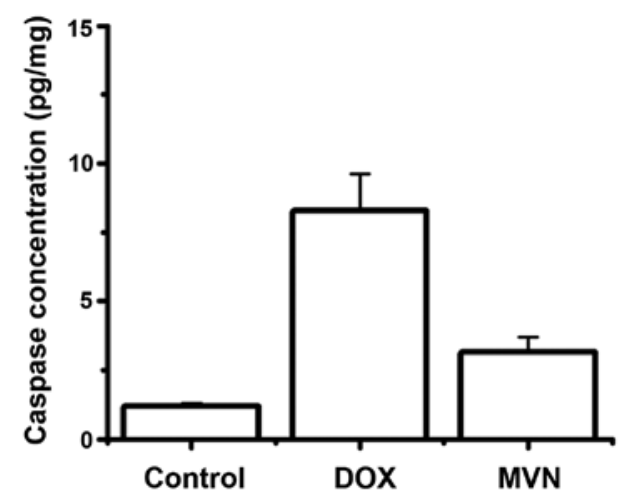

Figure 2. Effect of mevinolin (MVN) and doxorubicin (DOX) on the apoptosis effective phase (caspase- 3 activity) in MCF-7 cells. Caspase-3 activity was assessed on MCF-7 cells following treatment with DOX and MVN. Data are presented as means \pm standard deviation $(n=3)$.

cDNA synthesis, labeling and target preparation. cDNA was produced from total RNA using the GeneAtlas ${ }^{\mathrm{TM}}$ 3' IVTExpress $^{\prime}$ kit (Affymetrix, Inc., Santa Clara, CA, USA) according to the manufacturer's instructions. Second-strand cDNA synthesis, biotin-labeled aRNA synthesis (IVT Labeling) and RNA fragmentation were performed by Affymetrix GeneAtlas ${ }^{\circledR}$ kit reagents according to the procedure described in The GeneAtlas $^{\mathrm{TM}}$ 3' IVT Express kit User Manual.

Target hybridization and scanning. Biotin-labeled and fragmented target RNA samples were loaded into Affymetrix HG-U219 Array Strip ${ }^{\circledR}$ (Affymetrix, Inc.) together with poly-A control RNA and the oligomer B2. The hybridization procedure was conducted at $45^{\circ} \mathrm{C}$ for $16 \mathrm{~h}$ in the GeneAtlas ${ }^{\mathrm{TM}}$ Hybridization Station. The washing and staining procedure was performed in a GeneAtlas ${ }^{\mathrm{TM}}$ Fluidics Station with phycoerythrin-conjugated streptavidin (SAPE) according to the manufacturer's instructions. The GeneAtlas ${ }^{\mathrm{TM}}$ Imaging Station was used for scanning the arrays, exactly as described in the Affymetrix GeneAtlas ${ }^{\circledR}$ protocol.

Preliminary analysis of the scanned chips. Analysis was performed using Partek Express software (Ryoka Systems Inc., Tokyo, Japan) which estimates gene significance difference by ANOVA. The quality of gene expression data was checked according to quality control criteria. Pathway Studio ${ }^{\circledR}$ Explore, Affymetrix Edition Version 1.1 software (Affymetrix, Inc.) was used for further data analysis and evaluation. Pathway Studio ${ }^{\circledR}$ Explore is a powerful visualization and analysis solution designed for use with genomic expression data.

Statistical analysis. Data are presented as mean \pm standard error of the mean. Analysis of variance (ANOVA) with LSD post-hoc test was used to test the significance using SPSS ${ }^{\circledR}$ for Windows, version 17.0.0 (SPSS, Inc., Chicago, IL, USA). For the cytotoxicity bar graph, a t-test was performed to compare the cytotoxicity of different concentrations to the control group and was described as the probability associated with a Student's paired t-test, with a two-tailed distribution. $\mathrm{P}<0.05$ was considered to indicate a statistically significant difference.

\section{Results and Discussion}

Evaluation of the anticancer effect of MVN against MCF-7. The MTT assay was used to assess the cytotoxicity of MVN against an MCF-7 solid tumor cell line. The treated MCF-7 cells showed an $\mathrm{IC}_{50}$ of $2.08 \mu \mathrm{g} / \mathrm{ml}$ after treatment with MVN (Fig. 1). This result indicated a promising cytotoxic effect relative to $\mathrm{IC}_{50}$ of the positive control DOX $(0.42 \mu \mathrm{g} / \mathrm{ml})$ reported previously by our laboratory (17).

Caspase-3 activity in MCF-7 following treatment with $I_{50}$ of DOX and MVN. Concentrations of active caspase-3 were measured to determine whether the apoptotic cascade was activated. In MCF-7 cells, treatment with DOX significantly increased caspase-3 activity by 8 -fold and $\mathrm{MVN}$ by 3 -fold compared to its original activity (Fig. 2).

Transcript abundance analysis of MVN-treated cells with microarrays. The aim of the experiment was to examine the gene expressions that are modulated using microarray in MVN-treated MCF-7 cells. To analyze the early stage of the pathway and network level, we treated MCF-7 cells with MVN for $4 \mathrm{~h}$. The microarray analysis was performed to investigate genes associated with triggering apoptosis in the MVN-treated MCF-7 cells. 
Table I. The gene list showing the fold-change of cell-cycle arrest-related genes.

\begin{tabular}{|c|c|c|c|c|}
\hline Entrez code & Gene symbol & Gene name & Fold change & P-value \\
\hline 9821 & $R B 1 C C 1$ & RB1-inducible coiled-coil 1 & -1.6 & 0.00008 \\
\hline 5925 & $R B 1$ & Retinoblastoma 1 & -1.6 & 0.00168 \\
\hline 1869 & $E 2 F 1$ & E2F transcription factor 1 & 1.4 & 0.00106 \\
\hline 83990 & $B R I P 1$ & BRCA1 interacting protein C-terminal helicase 1 & -1.7 & 0.00073 \\
\hline 580 & $B A R D 1$ & BRCA1-associated RING domain 1 & -1.3 & 0.00097 \\
\hline 890 & CCNA2 & Cyclin A2 & -1.1 & 0.09285 \\
\hline 9134 & CCNE2 & Cyclin E2 & -1.9 & 0.00040 \\
\hline 1029 & $C D K N 2 A$ & Cyclin-dependent kinase inhibitor 2A (melanoma, p16, inhibits CDK4) & -1.1 & 0.18641 \\
\hline 1647 & $G A D D 45 A$ & Growth arrest and DNA-damage-inducible, $\alpha$ & -1.3 & 0.00575 \\
\hline 4616 & $G A D D 45 B$ & Growth arrest and DNA-damage-inducible, $\beta$ & -1 & 0.04625 \\
\hline 4436 & MSH2 & MutS homolog 2, colon cancer, non-polyposis type 1 (E. coli) & -1.8 & 0.00060 \\
\hline 1019 & $C D K 4$ & Cyclin-dependent kinase 4 & 1.1 & 0.00075 \\
\hline
\end{tabular}

The quality of the microarray data were within good sample limits according to preliminary data analysis parameters, such as background and noise averages, percentage of present calls, presence of internal hybridization controls in increasing signals, presence of poly-A controls as decreasing signals and GAPDH to $\beta$-actin 30/50 signal ratios. Therefore, transcript abundance data were analyzed via the pathway following local normalization.

Cell-cycle arrest. Several gene transcripts present in MCF-7 cells that were involved in the regulation of cell-cycle activity were significantly altered when exposed to MVN. In addition, changes in the related cell-cycle regulatory proteins were detected. Regulation of the cell cycle including the decrease of $\mathrm{Rb}$ and E2F1 transcript abundance was observed. EF2 is required for cell-cycle progression. $\mathrm{Rb}$ is also involved in cell-cycle regulation and can inhibit E2F. GADD45 transcripts, which control the G2/M phase transition, were also reduced by MVN treatment. MVN-induced DNA damage also had an impact on damage repair regulating pathways. One member of DNA-mismatch repair systems, MSH2, was significantly reduced in transcript abundance. PCNA, a cell proliferation marker and a control point for DNA repair, was also reduced. Cyclin-dependent kinases (CDKs) determine cell progression through the cell cycle. Both CDK1 (regulating G2 to S and $\mathrm{G} 2$ to $\mathrm{M}$ ) and CDK4/6 (important for cell-cycle G1 phase progression) exhibited increased transcript abundance (Table I).

Cell proliferation. MVN-induced inhibition of cell proliferation was observed in MCF-7 cells. Specifically, MVN inhibited HMG-CoA reductase and farnesyl pyrophosphate transferase, which reduced the biosynthesis of isoprenoids such as FPP and GGPP, crucial intermediates in cell signaling, and differentiation and proliferation. These results provide evidence that statins may have beneficial effects by increasing NOS expression and activity during the atherosclerotic process. MVN altered the transcript abundance of the Rho and RAP family of small GTPases that function as signal transduction, actin skeleton and cell shape factors. Overexpression was associated with cell proliferation and metastasis (Table II).
Cellular metabolism. MVN treatment altered the transcript abundance-encoding proteins involved in the regulation of metabolic processes such as pentose-phosphate shunt; 6-phosphogluconate dehydrogenase, 6-phosphogluconolactonase, phosphopentoseisomerase; glycolysis: phosphatetrioseisomerase, glyceratephosphomutase, dihydrolipyllysine residue acetyltransferase; fatty acid biosynthesis enzyme-encoding transcripts were reduced in transcript abundances including; hydrolase, lipoyl synthase, fatty acid synthase, acetyl Co-A carboxylase and acyl carrier protein. Transcripts encoding the tricarboxylic acid cycle; succinate dehydrogenase, isocitrate dehydrogenase, pyruvate carboxylase and ATP citrate lyase, responsible for the synthesis of cytosolic acetyl-CoA were also reduced (Table III).

MVN-induced oxidative stress and ROS generation. The transcript abundances of NADPH oxidase, peroxidase, glutathione peroxidase and glutathione reductase were increased, while the expression of superoxide dismutase was downregulated (an antioxidant enzyme) (Table IV).

Apoptosis and cell death. MVN treatment was accompanied by the loss of cell viability. Functional clustering facilitated the identification and subsequent inclusion of a large group of proteins associated with apoptosis signaling. This group included tumor necrosis factor (TNF) family members, $T N F R$ (fas), and TNFRAP (TRADD) activated by stress. In addition, the transcript abundance of $\mathrm{p} 53$ was increased. The $\mathrm{p} 53$ protein was involved in tumor suppression and was activated as a transcription factor in response to oncogene activation, hypoxia and DNA damage, resulting in growth arrest and/or apoptosis. Akt and MDM2 were decreased in abundance. Interaction of these proteins was central to $\mathrm{p} 53$ regulation. Several oncogenes were increased in transcript abundance including $C h k 2, A T M$, Ras and Raf. MVN also altered the transcript abundance of pro-apoptotic genes $(B A X, N O X A, B I D, A P A F-1)$, and the transcript abundance of antiapoptotic proteins, $(B c l-2, B c l-X L$ and $A I P$ or surviving). MVN increased the transcript abundance of cytochrome $c$. Transcript abundances of P38 and MAPK were increased likely due to the transduction of extra cellular 
Table II. The gene list showing the fold-change of cell growth and proliferation-related genes.

\begin{tabular}{|c|c|c|c|c|}
\hline Entrez code & Gene symbol & Gene name & Fold-change & P-value \\
\hline 5111 & PCNA & Proliferating cell nuclear antigen & -1.1 & 0.13414 \\
\hline 2099 & ESRl & Estrogen receptor 1 & -1 & 0.00008 \\
\hline 3485 & $I G F B P 2$ & Insulin-like growth factor binding protein $2,36 \mathrm{kDa}$ & 1.1 & 0.00005 \\
\hline 3488 & $I G F B P 5$ & Insulin-like growth factor binding protein 5 & -1.1 & 0.02736 \\
\hline 1956 & $E G F R$ & $\begin{array}{l}\text { Epidermal growth factor receptor } \\
\text { [erythroblastic leukemia viral (v-erb-b) oncogene] }\end{array}$ & -1 & 0.04490 \\
\hline 2260 & FGFRI & Fibroblast growth factor receptor 1 & -1 & 0.80737 \\
\hline 11116 & FGFRIOP & FGFR1 oncogene partner & -1.3 & 0.00248 \\
\hline 7048 & $T G F B R 2$ & Transforming growth factor, $\beta$ receptor II (70/80 kDa) & -1.1 & 0.01276 \\
\hline 54509 & RHOF & Ras homolog gene family, member F (in filopodia) & 1.3 & 0.13142 \\
\hline 391 & RHOG & Ras homolog gene family, member G (Rho G) & 1.3 & 0.01589 \\
\hline 29984 & RHOD & Ras homolog gene family, member D & 1.3 & 0.00112 \\
\hline 5911 & $R A P 2 A$ & RAP2A, member of RAS oncogene family & -1.6 & 0.00088 \\
\hline 5912 & $R A P 2 B$ & RAP2B, member of RAS oncogene family & -1.2 & 0.03266 \\
\hline 3156 & $H M G C R$ & 3-hydroxy-3-methylglutaryl-CoA reductase & -1 & 0.0259 \\
\hline 2339 & FNTA & Farnesyltransferase, CAAX box, $\alpha$ & -1.4 & 0.00179 \\
\hline 2342 & FNTB & Farnesyltransferase, CAAX box, $\beta$ & 1.1 & 0.23093 \\
\hline
\end{tabular}

Table III. The gene list showing the fold-change of cellular metabolism-related genes.

\begin{tabular}{|c|c|c|c|c|}
\hline Entrez code & Gene symbol & Gene name & Fold-change & P-value \\
\hline 5226 & $P G D$ & Phosphogluconate dehydrogenase & 1.5 & 0.00000 \\
\hline 6120 & $R P E$ & Ribulose-5-phosphate-3-epimerase & -1.5 & 0.00002 \\
\hline 22934 & RPIA & Ribose 5-phosphate isomerase A & -1.2 & 0.00570 \\
\hline 25796 & $P G L S$ & 6-Phosphogluconolactonase & 1.4 & 0.00000 \\
\hline 192111 & PGAM5 & Phosphoglyceratemutase family member 5 & 1.4 & 0.48600 \\
\hline 7167 & TPII & Triosephosphateisomerase 1 & 1.2 & 0.00091 \\
\hline 1737 & $D L A T$ & Dihydrolipoamide S-acetyltransferase & -1.3 & 0.00184 \\
\hline 11019 & LIAS & Lipoic acid synthase & -1.2 & 0.10000 \\
\hline 2194 & FASN & Fatty acid synthase & 1.2 & 0.00983 \\
\hline 6389 & $S D H A$ & Succinate dehydrogenase complex, subunit A, flavoprotein (Fp) & 1.2 & 0.04940 \\
\hline 3418 & $I D H 2$ & Isocitrate dehydrogenase 2 (NADP+), mitochondrial & 1.4 & 0.02310 \\
\hline 3420 & $I D H 3 B$ & Isocitrate dehydrogenase $3(\mathrm{NAD}+) \beta$ & 1.2 & 0.00194 \\
\hline
\end{tabular}

Table IV. The gene showing the fold change of ROS-related genes.

\begin{tabular}{|c|c|c|c|c|}
\hline Entrez code & Gene symbol & Gene name & Fold-change & P-value \\
\hline 10811 & NOXAl & NADPH oxidase activator 1 & 1.2 & 0.17500 \\
\hline 2877 & $G P X 2$ & Glutathione peroxidase 2 (gastrointestinal) & 1.2 & 0.00675 \\
\hline 2878 & $G P X 3$ & Glutathione peroxidase 3 (plasma) & 1.3 & 0.00412 \\
\hline 2879 & $G P X 4$ & Glutathione peroxidase 4 (phospholipid hydroperoxidase) & 1.3 & 0.00001 \\
\hline 2936 & GSR & Glutathione reductase & 1.1 & 0.00961 \\
\hline 6647 & SOD1 & Superoxide dismutase 1 , soluble & -1.1 & 0.00003 \\
\hline 4842 & NOS1 & Nitric oxide synthase 1 (neuronal) & 1.2 & 0.88300 \\
\hline 51070 & NOSIP & Nitric oxide synthase interacting protein & 1.1 & 0.26400 \\
\hline
\end{tabular}

ROS, reactive oxygen species. 
Table V. The gene list showing the fold-change of apoptosis-related genes.

\begin{tabular}{|c|c|c|c|c|}
\hline Entrez code & Gene symbol & Gene name & Fold-change & P-value \\
\hline 7157 & TP53 & Tumor protein $\mathrm{p} 53$ & 1.4 & 0.01360 \\
\hline 596 & $B C L 2$ & B-cell CLL/lymphoma 2 & -1.3 & 0.20900 \\
\hline 9530 & $B A G 4$ & BCL2-associated athanogene 4 & -1.3 & 0.00322 \\
\hline 7132 & TNFRSF $1 A$ & Tumor necrosis factor receptor superfamily, member 1A & 1.2 & 0.51300 \\
\hline 51330 & TNFRSF $12 A$ & Tumor necrosis factor receptor superfamily, member $12 \mathrm{~A}$ & 1.2 & 0.00040 \\
\hline 8795 & TNFRSF1OB & Tumor necrosis factor receptor superfamily, member $10 \mathrm{~b}$ & 1.1 & 0.04220 \\
\hline 4982 & TNFRSF 11B & Tumor necrosis factor receptor superfamily, member $11 \mathrm{~b}$ & -1.3 & 0.00413 \\
\hline 7128 & TNFAIP3 & Tumor necrosis factor, $\alpha$-induced protein 3 & -1.4 & 0.96500 \\
\hline 84231 & TRAF7 & TNF receptor-associated factor 7 & 1.2 & 0.00033 \\
\hline 9531 & $B A G 3$ & BCL2-associated athanogene 3 & 1.1 & 0.00182 \\
\hline 663 & $B N I P 2$ & BCL2/adenovirus E1B $19 \mathrm{kDa}$ interacting protein 2 & -1.4 & 0.00448 \\
\hline 1613 & $D A P K 3$ & Death-associated protein kinase 3 & 1.1 & 0.24500 \\
\hline 5134 & $P D C D 2$ & Programmed cell death 2 & -1 & 0.00509 \\
\hline 11235 & PDCD10 & Programmed cell death 10 & -1.7 & 0.00005 \\
\hline 27250 & PDCD4 & Programmed cell death 4 (neoplastic transformation inhibitor) & -1.3 & 0.00146 \\
\hline 4791 & $N F K B 2$ & $\begin{array}{l}\text { Nuclear factor of } \kappa \text { light polypeptide gene } \\
\text { Enhancer in B-cells } 2(\mathrm{p} 49 / \mathrm{p} 100)\end{array}$ & 1.1 & 0.04780 \\
\hline 208 & $A K T 2$ & V-akt murine thymoma viral oncogene homolog 2 & 1.2 & 0.01400 \\
\hline 64400 & $A K T I P$ & AKT-interacting protein & -1 & 0.00130 \\
\hline 4193 & $M D M 2$ & Mdm2 p53 binding protein homolog (mouse) & -1.1 & 0.04520 \\
\hline 23300 & $A T M I N$ & ATM interactor & -1 & 0.00038 \\
\hline 472 & $A T M$ & Ataxia telangiectasia mutated & 1 & 0.06510 \\
\hline 22821 & RASA3 & RAS p 21 protein activator 3 & -1 & 0.72500 \\
\hline 83593 & RASSF5 & Ras association (RalGDS/AF-6) domain family member 5 & 1.1 & 0.69500 \\
\hline 51285 & RASL12 & RAS-like, family 12 & -1 & 0.03010 \\
\hline 158747 & MOSPD2 & Motile sperm domain containing 2 & -1.8 & 0.00022 \\
\hline 1111 & CHEK1 & CHK1 checkpoint homolog (S. pombe) & 1.2 & 0.01450 \\
\hline 5286 & $P I K 3 C 2 A$ & Phosphoinositide-3-kinase, class $2, \alpha$ polypeptide & -1.8 & 0.04410 \\
\hline 8649 & $M A P K S P 1$ & MAPK scaffold protein 1 & -1.2 & 0.03410 \\
\hline 5594 & $M A P K 1$ & Mitogen-activated protein kinase 1 & -1.1 & 0.10000 \\
\hline 5595 & $M A P K 3$ & Mitogen-activated protein kinase 3 & 1.3 & 0.00031 \\
\hline 5601 & МАРК & Mitogen-activated protein kinase 9 & -1.1 & 0.00438 \\
\hline 5728 & PTEN & Phosphatase and tensin homolog & -1.4 & 0.00057 \\
\hline 638 & $B I K$ & BCL2-interacting killer (apoptosis-inducing) & 1.2 & 0.12700 \\
\hline 53335 & $B C L 11 A$ & B-cell CLL/lymphoma 11A (zinc finger protein) & -1 & 0.31100 \\
\hline 329 & $B I R C 2$ & Baculoviral IAP repeat-containing 2 & -1.4 & 0.00026 \\
\hline 317 & $A P A F 1$ & Apoptotic peptidase activating factor 1 & 1.1 & 0.57200 \\
\hline 1537 & CYCl & Cytochrome c-1 & 1.3 & 0.00097 \\
\hline 823 & CAPN1 & Calpain $1,(\mathrm{mu} / \mathrm{I})$ large subunit & 1.3 & 0.00552 \\
\hline 841 & CASP8 & Caspase-8, apoptosis-related cysteine peptidase & 1.1 & 0.03120 \\
\hline 837 & CASP4 & Caspase- 4 , apoptosis-related cysteine peptidase & 1 & 0.50200 \\
\hline 836 & CASP3 & Caspase-3, apoptosis-related cysteine peptidase & -1.1 & 0.96700 \\
\hline 835 & CASP2 & Caspase-2, apoptosis-related cysteine peptidase & 1.1 & 0.15100 \\
\hline 2021 & ENDOG & Endonuclease G & 1.4 & 0.00000 \\
\hline 842 & $C A S P 9$ & Caspase-9, apoptosis-related cysteine peptidase & 1.2 & 0.00003 \\
\hline 839 & CASP6 & Caspase-6, apoptosis-related cysteine peptidase & -1.1 & 0.01460 \\
\hline
\end{tabular}

signals and stress. $C y c D$ (regulator for $C D K 4$ and $C D K 6$ ) and $C y c$, a transporter for organic ion, were increased in transcript abundance. Caspase- 8 and -9 were increased in transcript abundance (Table V).
The significance of statins in preventing various types of cancer has been previously reported (18). Cholesterol and its draft is crucial for cell membrane stability and the synthesis of steroid hormones. Biomedical studies in the last two decades 


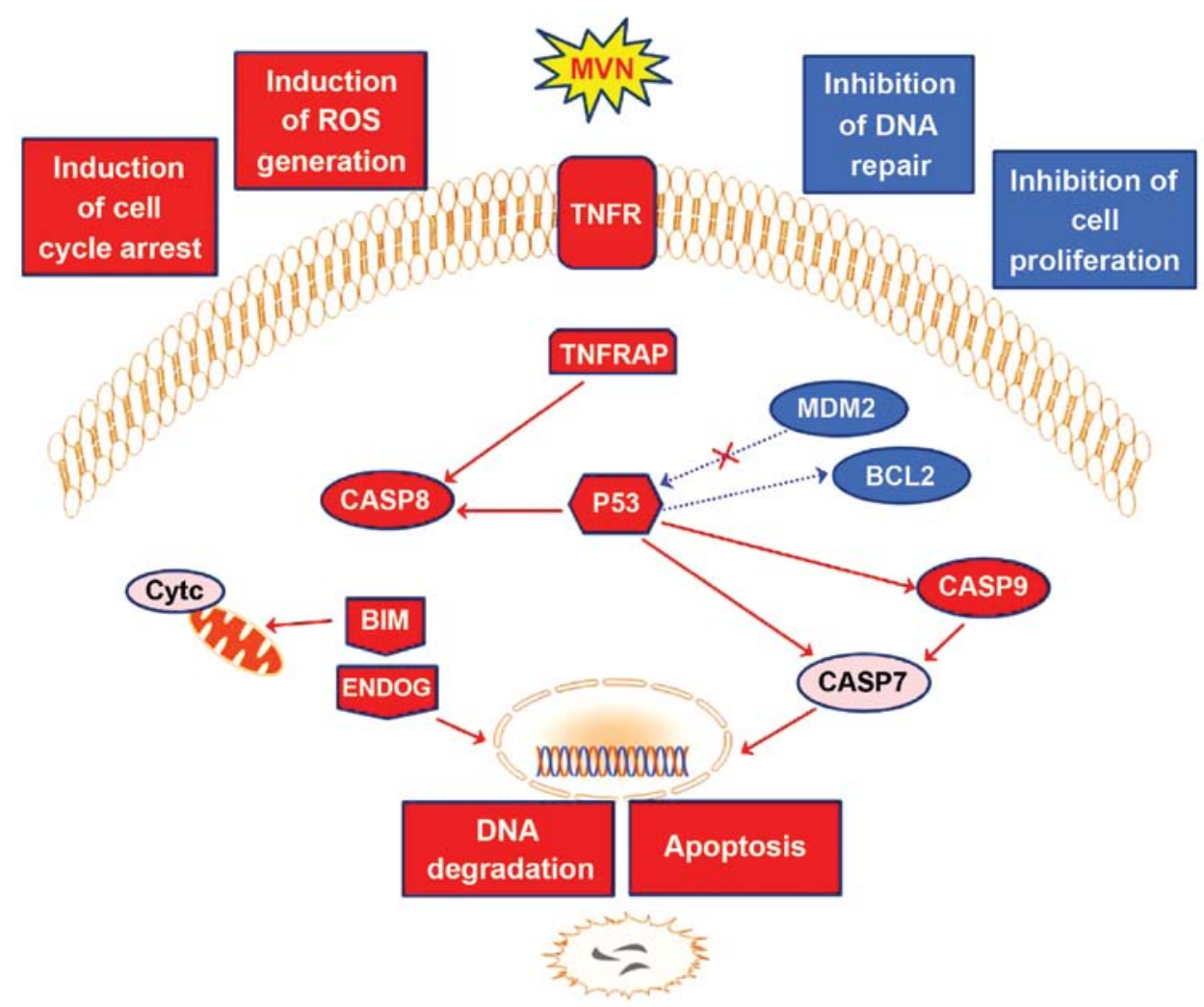

Figure 3. Schematic diagram summarizing the effects of MVN on signaling pathways as found in the present study. Blue, significantly reduced transcript abundances. Red, increased transcript abundances. Red arrows, induction effects in protein expression or activity. Dotted arrows, inhibitory effects. MVN, mevinolin; TNFR, tumor necrosis factor receptor; TNFRAP, TNFR adaptor protein; P53, tumor suppressor protein p53; Casp7, 8 and 9, apoptosis-related cysteine peptidases 7, 8 and 9; MDM2, p53 binding protein homolog; BCL2, B-cell cell/lymphoma 2; Bim, BCL2-like 11 (apoptosis facilitator); ENDOG, endonuclease G; Cyt c, cytochrome $c$.

have demonstrated the influence of MVN and cholesterol metabolites on cell proliferation and growth. Increasingly, the geranylgeranyl pyrophosphate, another important mevalonate pathway product, is affected by statins and its targets Rho and Rac (small guanosine 5'-triphosphate binding proteins associated with Ras statins). This mevalonate pathway appears to be an important key in tumor apoptosis $(19,20)$.

Steroidogenesis and cholesterol transport were suggested to be essential for the growth and proliferation of tumor cells (21). Steroidogenesis inhibition and the disruption of geranylgeranyl pyrophosphate-dependent survival pathways were attributed to the anti-proliferative effects of simvastatin, another HMGCo-A reductase inhibitor (22). Additionally, the association between the statins in general and the low incidence of carcinogenesis supported this hypothesis (11). Interference with the mevalonate pathway (prenylation) was known with its complexity to affect several apoptotic signaling pathways (19). Furthermore, MVN and other statins affect cell viability via mixed apoptotic and necrotic pathways at the same time (20). The efficacy of MVN against MCF-7 may be partly attributed to the multiplicity of its target signaling pathways (Fig. 3).

The safety profile of MVN in the experimental and clinical stages were encouraging for further clinical trials for the treatment of various types of tumors. The dose of MVN suggested for anti-cancer treatments was believed to be clinically safe $(6,7)$. Therefore, extremely high doses of MVN administered every $4 \mathrm{~h}$ to patients are considered tolerable (19). Consequently, MVN and other natural statins may be an improved treatment option for cancer as compared to synthetic statins (23).

MVN treatments inhibited DNA repair machinery, mRNA processing, translation and DNA recombination and induced cell cycle arrest. An increase in transcript abundances of GST (glutathione S-transferase) was observed. Although GST-Pi showed no significant alteration, it was active in the detoxification of ROS-induced damage. Increased NO levels and NOS were involved in generating oxidative stress. Cancer cells were more sensitive than normal cells to the effects of MVN on the transcript abundance of $\mathrm{HMG}-\mathrm{CoA}$ reductase. HMG CoA reductase is able to alter some key cellular processes, inducing the multi-factorial stress caused by MVN.

The microarray results, showed that the physiological activity of MVN on apoptosis induction can be ascribed, not only to the p53 pathway, but also to additional mechanisms. Therefore, we undertook gene expression analysis using microarray. Apoptosis has received attention as a major mechanism of cell death in normal as well as tumor cells. However, programmed cell death may be interrupted due to defective signaling pathways in tumor cells with higher rates of mutation (24). Defective apoptosis has been reflected in the cell resistance to apoptotic-inducing agents and, consequently, treatment failure. In addition, caspase- 3 activity was measured and the results indicated that in the cancer cells treated with MVN the activity of caspase-3 was significantly increased. These findings were supported by transcript abundance analyses. Investigations from our group have previously shown that the apoptotic process in 
MVN-treated cells is mediated by differential transcript abundances, which is controlled by multi-factorial changes (17). In this context, we conducted qPCR analysis of apoptosis-related genes in MVN-treated MCF-7 cells. Notably, the transcript abundances of a pro-apoptotic gene $(B A X)$, an anti-apoptotic gene $(B c l 2)$ and the key gene of apoptosis ( $p 53)$ were quantified using the qPCR technique in MCF-7 cells treated for $72 \mathrm{~h}$ with the $\mathrm{IC}_{50}$ of the cytotoxic drug DOX or MVN (17). It was found that there was increased $B c L 2$ but decreased BAX transcript abundance. By contrast, MVN treatment did not change the transcript abundance of $B A X$, but decreased the $B c L 2$ transcript abundance. Consequently, the p53 encoding transcript was increased in MVN-treated cells. In addition, MVN-treated cells were altered by oncogene expression, DNA damage, ROS generation or other forms of stress (16).

MVN has been suggested to induce cell death via multiple apoptotic (14), necrotic (20) and autophagic pathways (15). MCF-7 seemed to undergo apoptosis via the p53-dependent pathway. That finding is in concordance with that of a previous study by Lee and coworkers (25) who demonstrated ameliorated cytotoxic effects of simvastatin in p53 knockdown clones of HCT116 colon cancer cell lines (23). Similarly, the cytotoxic effects of MVN have been found in more than one cancer cell line and were p53-independent in nature $(26,27)$. This may also explain the ability of MVN to overcome K-Ras mutation in human non-small lung cancer (16). Additionally, Freed-Pastor and colleagues (28) studied the effects of mutated p53 on breast cancer cells. They showed that depletion of the mutated form of p53 reverses the oncogenic potential of breast cancer cell lines by inducing a normal-like phenotype characterized by the formation of acini-like structures.

In conclusion, MVN-induced antineoplastic effects against breast cancer cells were identified to be multi-factorial, possibly involving several regulatory pathways. The findings of the present study clearly support the potential use of MVN as a natural, safe and cost-effective anticancer drug compared to other traditional benchmarked chemotherapeutic drugs. Therefore, pre-clinical trials are fundamentally important to further investigate the selectivity of MVN and whether side effects may be present in healthy neoplasm-free cells. Furthermore, MVN efficacy and therapeutic potential may be maximized if this potential could be specifically delivered to the tumor mass.

\section{Acknowledgements}

We would like to thank the Alliance for Research on North Africa (ARENA) center at Tsukuba University for hosting Ali M. Mahmoud and we would like to thank Mr. Abdel-Hay G. Abu-Hussein, Cairo University Research Park, Cairo University, and Dr Sonya Tsolmon, ARENA Centre, University of Tsukuba, for their technical support. This study was financially supported by the Japan Society of Promotion of Science (JSPS) via the Asia-Africa Science-Platform Program and by King Saud University Vice Deanship of Research Chairs.

\section{References}

1. El-Shemy HA, Aboul-Enein AM, Aboul-Enein KM and Fujita K: Willow leaves' extracts contain anti-tumor agents effective against three cell types. PLoS One 2: e178, 2007.
2. Nassr-Allah AA, Aboul-Enein AM, Aboul-Enein KM, Lightfoot DA, Cocchetto A and El-Shemy HA: Anti-cancer and anti-oxidant activity of some Egyptian medicinal plants. J Med Plants Res 3: 799-808, 2009.

3. Hong MY, Seeram NP, Zhang Y and Heber D: Anticancer effects of Chinese red yeast rice versus monacolin $\mathrm{K}$ alone on colon cancer cells. J Nutr Biochem 19: 448-458, 2008.

4. Kumari HPM, Naidu KA, Vishwanatha S, Narasimhamurthy K and Vijayalakshmi G: Safety evaluation of Monascus purpureus red mould rice in albino rats. Food Chem Toxicol 47: 1739-1746, 2009.

5. Folkers K, Langsjoen P, Willis R, Richardson P, Xia LJ, Ye CQ and Tamagawa H: Lovastatin decreases coenzyme Q levels in humans. Proc Natl Acad Sci USA 87: 8931-8934, 1990.

6. Yang L, Wang Y, Lv TJ, Zhou LQ and Jin J: Effects of clinically effective dose of lovastatin on prostate cancer PC3 cells. Beijing Da Xue Xue Bao 42: 391-395, 2010 (In Chinese).

7. Yao CJ, Lai GM, Chan CF, Cheng AL, Yang YY and Chuang SE: Dramatic synergistic anticancer effect of clinically achievable doses of lovastatin and troglitazone. Int J Cancer 118: 773-779, 2006.

8. Shannon J, Tewoderos S, Garzotto M, Beer TM, Derenick R, Palma A and Farris PE: Statins and prostate cancer risk: a case-control study. Am J Epidemiol 162: 318-325, 2005.

9. Hamilton RJ, Banez LL, Aronson WJ, Terris MK, Platz EA, Kane CJ, Presti JC Jr, Amling CL and Freedland SJ: Statin medication use and the risk of biochemical recurrence after radical prostatectomy: Results from the Shared Equal Access Regional Cancer Hospital (SEARCH) Database. Cancer 116: 3389-3398, 2010.

10. Self TH and Akins D: Dramatic reduction in lipoma associated with statin therapy. J Am Acad Dermatol 58 (Suppl 2): S30-S31, 2008.

11. Farwell WR, Scranton RE, Lawler EV, Lew RA, Brophy MT, Fiore LD and Gaziano JM: The association between statins and cancer incidence in a veterans population. J Natl Cancer Inst 100: 134-139, 2008.

12. Riganti C, Doublier S, Costamagna C, Aldieri E, Pescarmona G, Ghigo D and Bosia A: Activation of nuclear factor-kappa B pathway by simvastatin and RhoA silencing increases doxorubicin cytotoxicity in human colon cancer HT29 cells. Mol Pharmacol 74: 476-484, 2008.

13. Perchellet JP, Perchellet EM, Crow KR, Buszek KR, Brown N, Ellappan S, Gao G, Luo D, Minatoya M and Lushington GH: Novel synthetic inhibitors of 3-hydroxy-3-methylglutarylcoenzyme A (HMG-CoA) reductase activity that inhibit tumor cell proliferation and are structurally unrelated to existing statins. Int J Mol Med 24: 633-643, 2009.

14. Klawitter J, Shokati T, Moll V, Christians U and Klawitter J: Effects of lovastatin on breast cancer cells: A proteo-metabonomic study. Breast Cancer Res 12: R16, 2010.

15. Sane KM, Mynderse M, Lalonde DT, Dean IS, Wojtkowiak JW, Fouad F, Borch RF, Reiners JJ Jr, Gibbs RA and Mattingly RR: A novel geranylgeranyl transferase inhibitor in combination with lovastatin inhibits proliferation and induces autophagy in STS-26T MPNST cells. J Pharmacol Exp Ther 333: 23-33, 2010.

16. Park IH, Kim JY, Jung JI and Han JY: Lovastatin overcomes gefitinib resistance in human non-small cell lung cancer cells with K-Ras mutations. Invest New Drugs 28: 791-799, 2010.

17. Mahmoud AM, Al-Abd AM, Lightfoot DA and El-Shemy HA: Anti-cancer characteristics of mevinolin against three different solid tumor cell lines was not solely p53-dependent. J Enzyme Inhib Med Chem 27: 673-679, 2012.

18. Boudreau DM, Gardner JS, Malone KE, Heckbert SR, Blough DK and Daling JR: The association between 3-hydroxy-3-methylglutaryl conenzyme A inhibitor use and breast carcinoma risk among postmenopausal women: A case-control study. Cancer 100: 2308-2316, 2004.

19. Mo H and Elson CE: Studies of the isoprenoid-mediated inhibition of mevalonate synthesis applied to cancer chemotherapy and chemoprevention. Exp Biol Med (Maywood) 229: 567-585, 2004.

20. Sánchez CA, Rodríguez E, Varela E, Zapata E, Páez A, Massó FA, Montaño LF and Lóopez-Marure R: Statin-induced inhibition of MCF-7 breast cancer cell proliferation is related to cell cycle arrest and apoptotic and necrotic cell death mediated by an enhanced oxidative stress. Cancer Invest 26: 698-707, 2008 . 
21. Hong MY, Seeram NP, Zhang Y and Heber D: Chinese red yeast rice versus lovastatin effects on prostate cancer cells with and without androgen receptor overexpression. J Med Food 11: 657-666, 2008.

22. Fuchs D, Berges C, Opelz G, Daniel V and Naujokat C: HMG-CoA reductase inhibitor simvastatin overcomes bortezomib-induced apoptosis resistance by disrupting a geranylgeranyl pyrophosphate-dependent survival pathway. Biochem Biophys Res Commun 374: 309-314, 2008.

23. Ahn KS, Sethi G and Aggarwal BB: Reversal of chemoresistance and enhancement of apoptosis by statins through down-regulation of the NF-kappaB pathway. Biochem Pharmacol 75: 907-913, 2008.

24. Tomiyama N, Matzno S, Kitada C, Nishiguchi E, Okamura N and Matsuyama $\mathrm{K}$ : The possibility of simvastatin as a chemotherapeutic agent for all-trans retinoic acid-resistant promyelocytic leukemia. Biol Pharm Bull 31: 369-374, 2008.
25. Lee SK, Kim YC, Song SB and Kim YS: Stabilization and translocation of $\mathrm{p} 53$ to mitochondria is linked to Bax translocation to mitochondria in simvastatin-induced apoptosis. Biochem Biophys Res Commun 391: 1592-1597, 2010.

26. Milkevitch M, Jeitner TM, Beardsley NJ and Delikatny EJ: Lovastatin enhances phenylbutyrate-induced MR-visible glycerophosphocholine but not apoptosis in DU145 prostate cells. Biochim Biophys Acta 1771: 1166-1176, 2007.

27. Martirosyan A, Clendening JW, Goard CA and Penn LZ: Lovastatin induces apoptosis of ovarian cancer cells and synergizes with doxorubicin: Potential therapeutic relevance. BMC Cancer 10: 103, 2010.

28. Freed-Pastor WA, Mizuno H, Zhao X, Langerød A, Moon SH, Rodriguez-Barrueco R, Barsotti A, Chicas A, Li W, Polotskaia A, et al: Mutant p53 disrupts mammary tissue architecture via the mevalonate pathway. Cell 148: 244-258, 2012. 